\title{
Semantic Organization of Information Resources for Supporting the Work of Academic Staff
}

\author{
Ilona Pawełoszek \\ Technical University of \\ Czestochowa, Al. Armii Krajowej \\ 36B 42-200 Częstochowa, Poland \\ Email: ipaweloszek@zim.pcz.pl
}

\begin{abstract}
The paper presents an on-going project in developing a semantic information portal for academic institution. The concept of a semantic platform called SemLib, grew out of many academic discussions and it reflects the information needs of researchers and educators from Technical University of Czestochowa. The proposed method of needs assessment is especially designed to create the starting point to build semantic structure of the digital library. The author proposes an approach for managing, organizing and populating knowledge by semanticizing existing information resources in the digital and traditional paper form. The prototyped solution is based on the Semantic MediaWiki software, that allows for cooperative resource building, maintaining and offers enhanced querying capabilities. Experimental results demonstrate the potentials of the proposed system as well as some obstacles that are the subject to improvement by further development of the SemLib platform.
\end{abstract}

$\mathrm{C}$ OLLABORATION and exchanging knowledge are vital to the effectiveness of the work of academic staff. In a world permeated with information technology and overwhelming amount of data there is a growing need to improve tools and methods of organizing information resources. The intelligent content management tools are crucial factor for every large organization.

In today's economy the universities play important roles of teaching and research. They are "central generators and repositories of knowledge in our society" [17 p.5].

At present it seems that the most successful research projects and most remarkable publications are characterized by their multidisciplinary environment and ability to tackle research challenges on a broader, wider scale. Effective collaboration and knowledge sharing requires the right information to be published and easily accessible to community members and external stakeholders (like enterprises and public administration seeking for academic partners to cooperate).

Discussions among academic community members reveal their unsatisfied information needs, and necessity for robust knowledge sharing and communication tools [16]. A remarkable improvement can be achieved by harnessing together Semantic Web and social networking tools. Such a combination is often referred to as Web 3.0 [18].

The aim of this paper is to present the concept of information portal based on Web 3.0 paradigm to organize informa- tion resources to support the university researchers and educators in their tasks. The main emphasis has been put on identifying and creating the semantic structure of the information resources in a way that would make them most useful and accessible.

\section{THE NEED FOR SEMANTIC ORGANIZATION OF INFORMATION}

University faculties often have hundreds of employees in teaching and scientific positions, whose tasks are "knowledge intensive" and require the access to the up to date resources including: books, journals, whitepapers, educative multimedia etc. A lot of these resources are created by the academics themselves and published in printed or electronic form. Even if the information is available, it may not be easily accessible, especially if we consider a large collection of information sources spanning diverse domains.

A number of discussions with academic staff of the Management Faculty of Technical University of Czestochowa revealed that the information in many cases is poorly accessible and the information flow between employees is impeded by the lack of appropriate IT solutions.

The activities like teaching, research, organizational tasks, writing publications and self-education, determine the information needs of the academics. Both the electronic and the printed form, appear to be poorly usable in terms of searching for particular information. Having hundreds of volumes such as manuals, conference proceedings, journals close at hand doesn't mean the information they contain is easily accessible. It is always easier to use search engine than to leaf through a book searching for a definition, reference or a person who is recognized as an authority on the given subject. The Author's own experience as well as the multiple discussions with coworkers acknowledge that even having the files in the electronic form (i.e.: pdf, doc or html files) is not very convenient for searching for particular information and it is one of the most time consuming task in the work of academics. Most of the local and global search engines serve a keyword-based method of finding information and are not able to respect the context of the query or to process the detailed query attributes. Finding information is a part of everyday work of every educator or scientist. 
There are many reasons arising from the policies of educational institutions as well as global circumstances that compel the authors to promote their work to be cited by other experts in their domain. On the other hand the authors are supposed to contribute to the domain knowledge, and take into account "the state of the art" of the subject they are working on. Therefore the scientiometric evaluation is important for all of the academics.

In all types of scholarly research it is necessary to attribute the author and the source of information that underpin particular concepts, positions and arguments with citations. This good practice is important due to a number of reasons:

- the citations help readers to identify and retrieve the source work to verify the information, or to learn more about issues and topics addressed by the work,

- citations provide the evidence that the subject is important and grounded in prior research,

- by citing one gives credit to the author of an original concept or theory presented.

For these reasons, it is important to build the systems that facilitate the bibliographic description of information cited in an organized and thorough manner. At the same time there is a growing need for creating effective search engines oriented towards supporting the retrieval of scientific information.

\section{THE CONCEPT OF SEMANTIC ORGANIZATION OF INFORMATION RESOURCES}

Currently the Semantic Web technology solutions are based on ontologies that describe the structure of domain instances, their classes, attributes, distinctions and relations. The term "ontology" in the context of information sciences and artificial intelligence is most often defined as an "explicit specification of conceptualization" [1]. Such specifications are necessary for knowledge representation and exchange [2]

A conceptualization can be defined as: an intentional semantic structure that encodes knowledge of a piece of some domain. Ontology is a (partial) specification of this structure, i.e., it is usually a logical theory that expresses the conceptualization explicitly in some language. Conceptualization is language independent, while ontology is language dependent. [3]. A shared or common ontology refers to an explicit specification of concepts [4, p.99] which can be used by a group of people or program agents in a multiagent system.

Ontologies can differ in terms of their expressiveness. Constructing ontology-based systems is time-consuming and must be realized by highly skilled staff - knowledge engineers cooperating with domain experts. For some applications it is worth the cost, i.e. investing a lot of time and effort in constructing a 'perfect' ontology, but in many cases this is not feasible [5 p.10]. There is always a need to balance the tradeoff between the complexity and the effort (and cost) of construction and maintaining of the ontology in question.
Thus there is a growing number of methodologies that specifically address the issue of ontology development and maintenance, for example:

- The methodology by Ushold and King [6] - worked out for the construction of Enterprise Ontology. The most interesting part of the methodology is the procedure of informal ontology development which is based on creativity techniques (brainstorming) to develop an informal ontology that can be easily understood and many people and works as a starting point to formalization.

- METHONTOLOGY by [7] is an example of evolutionary prototyping methodology that consists of a set of activities based on ontology life cycle and the prototype refinement;

- AFM:Activity-First Method in Hozo proposed by [8] is a method of building ontologies of tasks and domains by exploiting technical documentation. The task ontology provides the set of roles played by the users in the context of a given task. The domain concepts are organized according to the identified roles.

- 101 Method [9] is an iterative approach to ontology development. The method was worked out for the needs of development of wine and food ontology, using the Protégé2000 environment. The 101 method proposes four activities for the development of an ontology: (1 definition of the ontology classes; 2) organizing the taxonomy of classes; 3) defining properties of the classes and their permitted values, and 4) filling the attributes values for the instances.

It seems there is no just one best methodology for developing ontologies that would be useful in all cases and could become a standard. The above-mentioned methodologies extensively rely on human creativity and skills. Despite many semi-automatic approaches that have been developed, the ontology construction is still an art rather than craft.

The semi-automatic ontology construction is still a relatively new concept. These approaches are often referred to as ontology learning (OL) techniques. The example of such a semi-automatic approach is presented by [5], and focuses on constructing enterprise ontologies to be used for structuring and retrieving information related to a certain enterprise. The ontologies are quite 'light weight' in terms of logical complexity and expressiveness.

The semi-automatic ontology construction requires creating rather complicated algorithms based on NLP (Natural Language Processing) techniques, therefore these are specific methods for solving partial problems.

\section{The Methodology for Identification of Semantic STRUCTURE}

To the needs of our project (called SemLib - the abbreviation of Semantic Library) we decided to adapt and particularize the aforementioned general frameworks of manual ontology building based on human experience. The semantic organization of information resources can be defined as a process consisting of the following steps:

1. Gathering electronic documents and metadata about printed documents and objects. 
2. Identification of the semantic structure - a global structure of information in a document base.

3. Choosing a tool and a formal language for designing ontology and describing information resources.

4. Designing an ontology - network of semantic knowledge.

5. Applying the formal language to annotate the documents according to the structure identified in step 2 with the chosen tool.

Our methodology of organizing information resources is especially dedicated to the situations where there exists the set of documents that must be semanticized according to user's needs in a multidisciplinary users community.

Semantization of a document base means adding data and structure to the documents to make them understandable for intelligent search engines [see also: 19 p.70].

The first task is to decide about the scope of documents that are to be organized in the semantic structure. In our case the resources include:

- The users profiles containing the information about: the scientific degree, professional affiliation, interests, position. The users profiles already exist on the website of the university, but they are useless when it comes to search for the persons with particular attributes, professional background, interests etc.

- Publications: books, journals, whitepapers, reports, educative multimedia etc.

- Descriptions of research projects and grants - it is an important information while searching for partners with professional experience in particular field.

- Descriptions of external institutions cooperating in research project or education.

A lot of these resources are created by the academics themselves and published in printed or electronic form. Surprisingly both electronic and printed form, appear to be poorly usable in terms of searching for particular information. Having hundreds of volumes such as manuals, conference proceedings, journals close at hand doesn't mean the information they contain is easily accessible. Therefore the semantic organization of information resources is the prerequisite of semantic processing and searching.

Some of the aforementioned resources usually cannot be directly semanticized because their document format does not allow for adding annotations. Therefore in this case only the metadata can be the representation of the document on the semantic platform. The semantic platform plays the role of the catalog consisting of metadata of things that exist in a real world (employees, organization units, electronic and hardcopy documents). Some of the documents can be directly semanticized - the precondition is the possibility to transform the document to HTML format and having the copyright that allows to use, publish and edit the content.

The identification of the document base semantic structure can be performed in different ways. For example [10] propose systematic and automatic approach to ontology construction through the automatic identification of keywords from a corpus of randomly collected unstructured texts.
Different approach is presented in the study of [11]. The authors present an approach that starts with a list of relevant domain ontologies created by human experts, and techniques for identifying the most appropriate ontology to be extended with information from a given text.

Although the automatic approaches are very accurate they can be applied only to the texts in a specific domain. In our case study the documents are heterogeneous considering their domains and their structure. For example the descriptions of the academics, their scientific and professional attainment may differ significantly. On the other hand the descriptions of literature (journal articles, monographs and other publications) have quite similar bibliographic structure and can be easily cataloged using common metadata format like Dublin Core. The descriptions of projects realized by the academics can also be multidisciplinary and differ in terminology.

Therefore the automatic approach to ontology extraction would require to distinguish many categories and to run the procedure many times to extract separate ontologies. The next step would be mapping the ontologies because the documents from different categories are interrelated.

Taking into account the multidisciplinary character of the designed platform and the requirements of usability and maintainability we decided not to use automatic methods of ontology extraction and concentrate on recognizing the users' information needs as a base of ontology construction.

The semantic structure of the document base should be first of all meaningful and relevant for the users. The functions of the platform should be adjusted to the context of the work tasks of the users.

The next section describes the method for identifying the semantic structure in the context of the users work.

The aim of the designed solution is to fulfill the information needs of the users by exploiting the easily accessible document base with a semantic query interface. An information need is a gap in one's knowledge[12] that can be bridged by providing an answer to a question. Thus asking the users to specify the questions they ask while searching for information seems to be the most appropriate research method in this case. Table I summarizes the questions specified by 20 potential users of the system, the questions were assigned to the groups that represent categories of objects described in the document base. The categories reflect the areas of professional activities.

The areas of context are general categories (classes) of objects. Questions represent attributes and/or relations between objects.

For example finding "experts in particular domain" (let us call the domain: X) can possibly involve finding the persons who participated in conferences and projects in the domain $\mathrm{X}$ or teaching subject $\mathrm{X}$.

The next important thing to specify was the form and the particularity of the answer to our questions - what additional information is to be displayed. This additional information presents the context of the query (Table II).

In our example of finding experts in the given domain the query result could include: The names of the persons inter- 
TABLE I.

THE QUESTIONS SPECIFIED BY POTENTIAL USERS OF THE SYSTEM

\begin{tabular}{|c|c|c|c|c|c|c|c|c|c|}
\hline \multirow{3}{*}{$\begin{array}{l}\text { Question about: } \\
\text { Definitions }\end{array}$} & \multicolumn{9}{|c|}{ Categories of objects } \\
\hline & 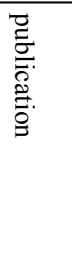 & $\begin{array}{l}\overrightarrow{9} \\
9 \\
9 \\
0 \\
0\end{array}$ & 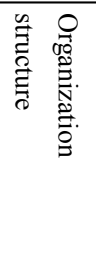 & 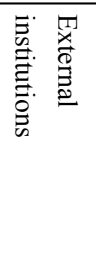 & 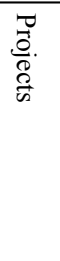 & 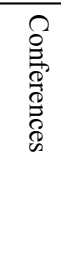 & 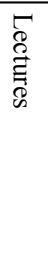 & 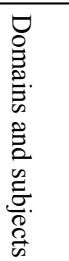 & 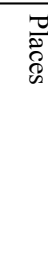 \\
\hline & $\mathrm{x}$ & & & & & & & $\mathrm{x}$ & \\
\hline Research results & $\mathrm{x}$ & & & & & & & $\mathrm{x}$ & \\
\hline Research methods & $\mathbf{x}$ & & & & & & & $\mathbf{x}$ & \\
\hline Citations & $\mathbf{x}$ & $\mathbf{x}$ & & & & & & & \\
\hline Scientific degree & & $\mathbf{x}$ & & & & & & & \\
\hline Workplace & & $\mathbf{x}$ & $\mathbf{x}$ & & & & & & $\mathbf{x}$ \\
\hline $\begin{array}{l}\text { Experts in particular } \\
\text { domains }\end{array}$ & $\mathbf{x}$ & $\mathbf{x}$ & & & $\mathbf{x}$ & & $\mathbf{x}$ & $\mathbf{x}$ & \\
\hline $\begin{array}{l}\text { Universities and } \\
\text { academic centers }\end{array}$ & & & & $\mathbf{x}$ & & & & & $\mathbf{x}$ \\
\hline $\begin{array}{l}\text { Articles about a given } \\
\text { subject }\end{array}$ & $\mathbf{x}$ & & & & & & $\mathbf{x}$ & $\mathbf{x}$ & \\
\hline Citations in articles & $\mathbf{x}$ & & & & & & & & \\
\hline $\begin{array}{l}\text { Taking part in projects as a } \\
\text { member of the team or leader }\end{array}$ & & $\mathbf{x}$ & & & $\mathbf{x}$ & & & $\mathbf{x}$ & \\
\hline $\begin{array}{l}\text { Conducting individual } \\
\text { research, }\end{array}$ & & $\mathbf{x}$ & $\mathbf{x}$ & & $\mathbf{x}$ & & & $\mathbf{x}$ & \\
\hline Participating at conferences, & $\mathbf{x}$ & $\mathbf{x}$ & & & & $\mathbf{x}$ & & & $\mathbf{x}$ \\
\hline $\begin{array}{l}\text { Authoring and co-authoring of } \\
\text { research papers, books, } \\
\text { chapters, etc. }\end{array}$ & $\mathbf{x}$ & $\mathbf{x}$ & & & & & & & \\
\hline $\begin{array}{l}\text { Editorialship of scientific } \\
\text { publications }\end{array}$ & $\mathbf{x}$ & $\mathbf{x}$ & & & & & & & \\
\hline $\begin{array}{l}\text { Educational Multimedia } \\
\text { resources }\end{array}$ & & & & & & & $\mathbf{x}$ & $\mathbf{x}$ & \\
\hline $\begin{array}{l}\text { Being in charge of } \\
\text { organizational units }\end{array}$ & & $\mathbf{x}$ & $\mathbf{x}$ & & & & & & $\mathbf{x}$ \\
\hline Cooperation with industry & & & & $\mathbf{x}$ & $\mathbf{x}$ & & $\mathbf{x}$ & $\mathbf{x}$ & $\mathbf{x}$ \\
\hline
\end{tabular}

ested in domain $\mathrm{X}$, the scientific degrees, the affiliations, number of citations, number of research projects.

\section{THE SEMANTIC SOFTwARE PlatForm}

In order to benefit fully from the networked information it is vital for organizations to have a single point knowledge shop for quality information with certainty, authority and consistency. [4, p.103]
Today's software platforms are designed with the architecture of participation in mind, this means they are meant for active user contribution in creation of content, functions and services. Web 2.0 platforms continuously grow in popularity due to the phenomenon of "network effect" which is driving force behind a number of users joining online communities [13].

Information portals allow easy access to heterogeneous data resources, applications and services in a consistent way. 
Portals may also improve corporate communication by exploiting various tools based on Web 2.0 paradigm. The semantically enhanced information portal SemLib for the community of academic staff was meant to be a user-centered web application exploiting selected Semantic Web technologies and adhering to the following requirements:

- Scalable and extensible architecture.

- The portal content should be created, reviewed, published, and managed by web Content Management System (CMS) using well-defined content authoring and publication process. web 2.0 architecture seems to be the best choice considering the large number of internal stakeholders and the dynamics of information (new publications will be added frequently).

- CMS should provide multiple authorization levels.

- Users, involved in editing, reviewing and publishing content.

- Easy semantic query interface - many Semantic Web technologies like RDF and OWL only offer a SPARQL query interface, which is difficult for users not having SPARQL expertise and no background in knowledge engineering.

- The portal should serve as a tool for promotion of scientific research and collaboration.

After considering the above requirements, we chose Semantic MediaWiki (SMW) as the platform to present the structured knowledge and manage the knowledge reasonably.

The aim of wiki is to organize and share information resources in a collaborative environment. Collaborative authoring is the effective way of creating knowledge proved by many examples, of which the most spectacular is Wikipedia. Apart from many advantages and flexibility, the MediaWiki platform is not free from shortcomings. The main disadvantage is the lack of knowledge structuring functionality. The answer to this shortcoming is Semantic Mediawiki package which is a set of extensions that provide semantic annotations and reasoning features.

The SMW achieves most of the requirements we preset while few of the requirements cannot be fulfilled and some of them cannot be directly realized. SMW is a free and open source extension of MediaWiki, released under the GNU Public License. SMW collects semantic data by letting users add annotations to the wiki source text of pages via a special markup [14].

The additional features of MediaWiki, such as the possibility of setting the authorization for the groups of users, and searching for historical changes extensively facilitates management tasks.

One of the most important advantages offered by Semantic MediaWiki is its semantic query language that lacks the complexity of SPARQL (e.g. querying within a particular namespace) [15].

Semantic MediaWiki has become the most popular semantic wiki engine by far, achieving several hundred installations worldwide and engaging an active open source developer community.

\section{V.The Semantic Structure of the SEMLib Platform}

The semantic structure defines the categories, subcategories and attributes of the entities described in the document base. The attributes can also be categories. The seman-

TABLE II.

EXAMPLE INFORMATION NEEDS AND CONTEXT PARAMETERS

\begin{tabular}{|l|l|}
\hline Needed information & Query context parameters \\
\hline definitions of concepts & $\begin{array}{l}\text { author, year of publication, Author's } \\
\text { affiliation }\end{array}$ \\
\hline $\begin{array}{l}\text { research reports and } \\
\text { results }\end{array}$ & $\begin{array}{l}\text { author, institution, year of publication, } \\
\text { geographical region, branch }\end{array}$ \\
\hline $\begin{array}{l}\text { citations of one's own } \\
\text { publications }\end{array}$ & years of the referencing work \\
\hline figures, tables, charts & $\begin{array}{l}\text { subject, year of publication, relevant } \\
\text { definition }\end{array}$ \\
\hline multimedia & $\begin{array}{l}\text { creator, subject, year of publication, file } \\
\text { type }\end{array}$ \\
\hline $\begin{array}{l}\text { bibliographic } \\
\text { references }\end{array}$ & $\begin{array}{l}\text { year and place of publication, isbn or issn, } \\
\text { author/authors }\end{array}$ \\
\hline $\begin{array}{l}\text { potential partners in } \\
\text { project realization or } \\
\text { coauthoring. }\end{array}$ & $\begin{array}{l}\text { people, interests, authorship, participation } \\
\text { in projects }\end{array}$ \\
\hline conferences & subject, place, publication type, price \\
\hline
\end{tabular}


tic structure was designed according to the users' information needs unveiled by the survey. The structure of the information needs were analyzed from the point of view of categories and attributes. Figure 1 presents the simplified class diagram with relations between categories defined and applied in the SemLib prototype platform. Some of the relations were omitted on a diagram to make it more legible. For example an article can be understood as a part of the journal or as the book chapter. We decided not to define the separate class for the entities like book chapter and article because they would have exactly the same attributes. Although it can be inferred that if an article is a part of the book it can be called a "chapter", so it would be possible to display the separate lists of articles and chapters if needed. The relation "is written by" can contain multiple values, each of the values points to one entity of the class "Author".

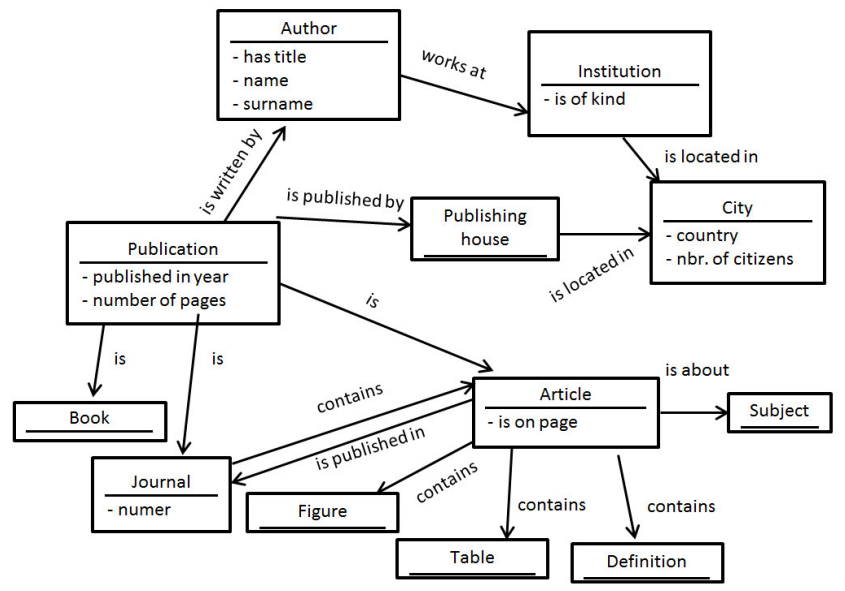

Fig. 1 Classes and relations in a prototype semantic platform

\section{Source: Own study}

The presented data model allows to ask compound queries respecting many context parameters.

The "subject" class that is used to categorize the content of publications, has many instances of the hierarchical structure. The example fragment of marketing subject class is:

- Marketing

o Customer relationship management

o Marketing mix

\&Promotion

\&Advertising

o Web marketing

o Customer service

The subjects hierarchy facilitates annotation tasks. For example if the described article is annotated with the tag "advertising", the search engine "knows" that the article is from the marketing domain although it may not be explicitly written in the page describing the given article.

Descriptions of example queries and their syntax are presented in table II.

The list displayed by the query 1 will also contain articles about promotion and advertising although they are not annotated with the word "marketing".
While designing the semantic portal based on SMW there is no need to define the whole categories structures in advance. For example the categories of subjects are created or developed when there is a need to describe the particular publication from a given domain. This ongoing iterative development approach will probably bring a better result of more accurate tagging if we assume that the authors will add their own publications in the domain of their expertise.

Analogously there is a possibility of searching for relations between projects, conferences and persons, so it is possible to list for example "all the publications from conference $\mathrm{Y}$ authored by person $\mathrm{X}$ " or "all the conferences in which the people from University C took part".

There are a lot of combinations of attributes and categories. Such lists can be settled according to date, place, institution, person and practically every attribute defined in the system. This functionality is very useful while preparing reports about activities of the University departments or individual employees.

Although the semantic wiki query syntax seems easy and intuitive thanks to its similarity to natural language the practice shows that after some time of disuse it is hard to remember the names of attributes used to pose the queries.

For now we are developing a help system in the form of example queries which users can modify according to their current needs. The example queries that were included in help system were chosen from the most often input queries. Additionally the users can use special wiki pages for listing the categories and attributes existing in the system. The namespace for special pages listing categories is: Special:Categories

\section{CONCLUSION AND FUTURE WORK}

The SemLib platform is very flexible and the directions of its evolution should be determined by analyzing the users' needs. The needs assessment method consisting in formulating example queries posed by users proved to be an appropriate and agile way to transform the users' needs to semantic categories and attributes.

The platform has been created and developed at Technical University of Czestochowa to complement the missing semantic functionalities of the existing information portals.

Probably the most time-consuming part of the discussed undertaking is the developing, maintaining and annotating the document base. Semanticizing the publications from conferences, journal articles and monographs is rather tedious task in spite of forms and templates that are accessible in Semantic MediaWiki interface. But the effort may turn out to be worthwhile if the portal brings results in facilitating collaboration and information access. It is hard to evaluate the success of the semantically enhanced portal in a quantitative way. Some measures can be applied, like: precision, recall, time spent to get answers to particular questions comparing to traditional keyword search or literature browsing, the number of emerging research teams or publications co-authored by groups using the SemLib platform.

At present the SemLib platform is continuously developed and it is perceived very promising and innovative. 
Having all the metadata at hand makes the work faster when it comes to find particular information in the library. It is also possible to prepare multiple reports from the scientific activities much faster. The future research directions can encompass the proposition of a detailed methodology of assessing the performance of the system.

Apart from all the advantages there are also some obstacles that are subject to further considerations and development. One of potential problems is the possibility of inaccurate annotations. An idea to overcome that problem is to engage the community of end-users. If we assume the users are experts in their subject it is undeniable that after a short training, they can do the tagging far more accurately than the system administrators who will only perform the controlling functions.

As the practice shows the wiki passive users (the persons who are not editors) encounter some difficulties in using SemLib. The most often reported one was the lack of knowledge about wiki functions in general. Not all of the users seem to understand the nature of the wiki and the need for respecting some organizational guidelines, e.g. using the categories and attributes defined earlier by other users. Moreover it is in the interest of the users to describe their own publications in a way that ensures they will be frequently found, retrieved, and consequently more often cited.

The SemLib would be far more useful if all the described resources (books, journals, articles) were accessible in electronic form and linked directly to the semantic wiki site where they are described. Transformation of all the library resources to electronic form is inevitable in the future, but it requires a lot of work and changes in the copyright law. The old fashioned fossil library catalogs of publications do not have a potential to reveal the full value of information resources they describe because their data models are not flexible and cannot be easily adapted to dynamic users' needs. The semantic technology along with cooperative editing tools like MediaWiki support a community of participants, who interact with the content to varying degrees based on their permissions. All participants can be creators, editors, and curators [20].

The SemLib platform is quite new project that is still in the development phase, but we continuously add new publications to the semantic base and at the same time we are working to expand the ontology of research topics.

We are working on the concept of the more intelligent query interface that is based on the idea of contextual hints displayed to the user after analyzing the part of the query that has been already input into the search box.

\section{REFERENCES}

[1] T. Gruber, A Translation Approach to Portable Ontology Specifications. Knowledge Acquisition. 5. 1993
[2] M. Obitko, Ontologies - Description and Applications. Report No. GL 126/01. Gerstner Laboratory for Intelligent Decision Making and Control Series of Research Reports. 2001. http://cyber.felk.cvut.cz/gerstner/reports/GL126.pdf

[3] Specification of Conceptualization Retrieved April 20, 2014, from http://www.obitko.com/tutorials/ontologies-semanticweb/specification-of-conceptualization.html

[4] Z Cui, V A M Tamma and F Bellifemine "Ontology management in enterprises", BT Technology Journal Vol 17 No 4 October 1999 pp. 98-107

[5] E. Blomqvist, "Semi-automatic Ontology Construction based on Patterns", Dissertation No. 1244, Linköping Studies in Science and Technology, Linköping 2009

[6] M. Uschold, M. King, "Towards a Methodology for Building Ontologies.Workshop on Basic Ontological Issues in Knowledge Sharing". 1995.

[7] A. Gómez-Pérez, M. Fernández López and Corcho O., "Ontological Engineering with Examples from the Areas of Knowledge Management, E-commerce and the Semantic Web". London: Springer 2004

[8] R. Mizoguchi, and J. Bourdeau, "Using Ontological Engineering to Overcome AI-ED Problems", International Journal of Artificial Intelligence in Education, Vol.11, No.2, pp.107-121, 2000.

[9] F. N. Noy, and D. L. Guinness, "Ontology development 101: A guide to create your first ontology". Stanford University, 2001. Retrieved April 20, 2014, from http://protege.stanford.edu/publications/ontology_development/ontolo gy101.pdf

[10] A. Khurshid and G. Lee "Automatic Ontology Extraction from Unstructured Texts" Retrieved April 20, 2014, from https://www.scss.tcd.ie/Khurshid.Ahmad/Research/OntoTerminology/ ODBASE2005.final.pdf

[11] Raghu Anantharangachar, Srinivasan Ramani, S Rajagopalan, "Ontology Guided Information Extraction from Unstructured Text", International Journal of Web and Semantic Technology (IJWesT) Vol.4, No.1, January 2013 Retrieved April 20, 2014, from http://arxiv.org/ftp/arxiv/papers/1302/1302.1335.pdf

[12] D. Nicholas: "Assessing Information Needs, tools, techniques and concepts for the Internet age", Taylor and Francis e-Library, 2005

[13] I. Pawełoszek, "Semantically Enhanced Information Portal for Community of University Researchers", Prace Naukowe UE we Wrocławiu nr 187, Informatyka Ekonomiczna nr 20. Wybrane zagadnienia. Wydawnictwo Uniwersytetu Ekonomicznego we Wrocławiu, Wrocław 2011.

[14] D. Vrandecic, „Ontology Evaluation” Retrieved April 20, 2014, from http://www.aifb.kit.edu/images/b/b5/OntologyEvaluation.pdf

[15] A. Dumitrache and C. Lange, "BauDenkMalNetz - Creating a Semantically Annotated Web Resource of Historical Buildings" Retrieved April 20, 2014, from http://ceur-ws.org/Vol-721/paper04.pdf

[16] D. Viehland, "ISExpertNet: Facilitating Knowledge Sharing in the Information Systems Academic Community", in: Issues in Informing Science and Information Technology pp 441-450, Retrieved June 17, 2014, from: http://proceedings.informingscience.org/InSITE2005/I36f30Vieh.pdf

[17] M. Abreu, V. Grinevich**, A. Hughes, M. Kitson and P. Ternouth, "Universities, Business and Knowledge Exchange" Council for Industry and Higher Education, and Centre for Business Research 2008, retrieved June 17, 2014, from: http://www.cbr.cam.ac.uk/pdf/University\%20Business\%20Knowledge $\% 20$ Exchange $\% 20 \mathrm{v} 7$.pdf

[18] P. Mika, "Social Networks and the Semantic Web", Springer 2007.

[19] R. M. Fay, M. P. Sauers, "Semantic Web Technologies and Social Searching for Librarians", Amercian Library Association 2012

[20] S. McNally, "Empowering the Distributed Editorial Workforce", In: M. Wolfgang, T. Kowatsch, (Eds.), "Semantic Technologies in Content Management Systems", Springer 2012. 